\title{
An emerging view of mastery, excellence, and leadership in occupational therapy practice.
}

Janice P Burke

Thomas Jefferson University

Elizabeth DePoy

University of Maine

Follow this and additional works at: https://jdc.jefferson.edu/otfp

Part of the Occupational Therapy Commons

Let us know how access to this document benefits you

\section{Recommended Citation}

Burke, Janice $P$ and DePoy, Elizabeth, "An emerging view of mastery, excellence, and leadership in occupational therapy practice." (1991). Department of Occupational Therapy Faculty Papers.

Paper 39.

https://jdc.jefferson.edu/otfp/39

This Article is brought to you for free and open access by the Jefferson Digital Commons. The Jefferson Digital Commons is a service of Thomas Jefferson University's Center for Teaching and Learning (CTL). The Commons is a showcase for Jefferson books and journals, peer-reviewed scholarly publications, unique historical collections from the University archives, and teaching tools. The Jefferson Digital Commons allows researchers and interested readers anywhere in the world to learn about and keep up to date with Jefferson scholarship. This article has been accepted for inclusion in Department of Occupational Therapy Faculty Papers by an authorized administrator of the Jefferson Digital Commons. For more information, please contact: JeffersonDigitalCommons@jefferson.edu. 


\section{An Emerging View of Mastery, Excellence, and Leadership in Occupational Therapy Practice}

\author{
Janice Posatery Burke, Elizabeth DePoy
}

\author{
Key Words: clinical competence • professional \\ competence $\bullet$ professional practice
}

The recent focus on clinical reasoning in occupation al therapy, specifically on bow therapists solve complex problems, has stimulated interest in bow master clinicians think in practice. By gaining insight into bow clinicians think and what they think about when they identify and solve problems, we may be able to identify clinical reasoning patterns and processes that occupational therapy students and novice therapists need to experience in order to progress in their practice or to emerge as leaders in their field. Observation of the way in which clinical masters and leaders view challenges and solve problems as manifested in their clinical reasoning may provide new and potential therapists with clues as to bow to best bone their skills and knowledge for future success in practice.

This paper describes a study that examined the relationship of mastery, excellence, and leadership in occupational therapy. Ten master clinicians were interviewed to determine the characteristics of their mastery and excellence in practice and to explore the degree to which they engaged in leadership bebavior. The findings revealed that mastery, excellence, and leadership are independent of one another but that some characteristics are common to all of these phenomena.

Janice Posatery Burke, MA, OTR儿, FAOTA, is Assistant Professor, Department of Occupational Therapy, Thomas Jefferson University, 130 South Ninth Street, Edison 820, Philadelphia, Pennsylvania 19107.

Elizabeth DePoy, PhD, MSW, OTk, is Assistant Professor, Department of Social Work, University of Maine, Orono, Maine.

This article was accepted for publication July 2, 1991.
$\mathrm{O}$ ccupational therapists have had to consider the issue of professionalization as the field strives to develop and implement strategies to meet the changing financial and structural demands of the current health care industry. As occupational therapists have moved toward professionalization, they have become increasingly concerned with the process of distinguishing their uniqueness from that of other members of the health care team.

Clarification and identification of professional behavior has a twofold benefit: It gives important information to those within the profession who wish to emulate such behavior, and it offers definition to those outside the profession who scrutinize our professional worth. In conjunction with the traditional methods by which occupational therapy and its domain of concern are defined (i.e., description of practice methods, treatment, and assessment techniques), an understanding of the clinical reasoning process may reveal the unique ways that occupational therapists come to assess and seek solutions to patients' problems and to delimit the scope of their practice to what is uniquely occupational therapy. Clinical reasoning addresses many of the unstated thoughts and formulations that therapists develop when they work with patients. The therapist's ability to decide which of the patient's needs to address and how to construct the most meaningful treatment opportunities often depends on more than a set of explicit rules. Intuition, judgment, empathy, and common sense, all aspects of the clinical reasoning process, are among the many strategies a therapist may use to develop and evaluate individualized treatment plans. An examination of the character and spirit of practitioners who demonstrate mastery, excellence, and leadership illuminates the clinical reasoning processes and clinical practices that are essential to professional excellence and growth.

A study of clinical nurse specialists revealed the association between clinical reasoning and mastery in practice (Benner, 1984; Benner \& Tanner, 1987). Experienced nurse specialists were found to use a more sophisticated level of clinical reasoning than their less-experienced counterparts. We were interested in finding out whether this was true for master clinicians in occupational therapy, thus we sought to describe the behavior of master clinicians.

In addition to the fostering of clinical mastery in occupational therapy, there is increased demand both within and outside the profession to prepare therapists for key positions in all domains of professional activity, that is, in the clinic, in education, and in research as well as in the professional and political communities. In her look at professionalism, Parham (1987) urged that we "seize whatever opportunities are available that will enable us to take responsibility for the future of occupational therapy. For some of us, those opportunities will arise in practice; for others, in education, political action, or 
research and scholarship" (p. 555). In describing the behavior of master clinicians, it appeared to Parham that behaviors such as excellence and leadership might also be revealed as they relate to the experienced therapist.

\section{Uncovering Mastery, Excellence, and Leadership}

With increasing concern about accountability and a strong desire to understand how health care practitioners make decisions and solve complex problems, mastery, excellence, and leadership have come into focus in health professions in general and in occupational therapy in particular. DePoy (1990) found that, in occupational therapy, mastery consists of a set of personal characteristics (e.g., creativity, commitment to practice, intelligence) combined with identifiable patient outcomes and an individual and creative reasoning style. Mattingly (1990), Fleming (1991), Rogers and Masagatani (1982), and Barris (1987) are among those who have studied clinical reasoning in both occupational therapy assessment and treatment to describe and analyze the unique methods that therapists use when working with patients. Their results provide an emerging view of the therapist in action.

The increased attention and interest in how clinicians think and make decisions is reflected in the recent surge of literature and research on clinical reasoning (Burke, 1989; Cohn, 1989; Fleming, 1991; Gillette \& Mattingly, 1987; Neistadt, 1987; Neuhaus, 1988). Among the questions being asked is whether student, beginning, novice, or experienced therapists can be given both knowledge and specific experiences that will assist them in developing efficient and effective methods for solving patients' problems. By examining the ways in which therapists think when they achieve successful treatment and consultation, we can better understand the practice of occupational therapy and infuse the next generation of practitioners with strategies for achieving the same success. Furthermore, in understanding the work of master clinicians, we may learn about the kinds of experiences therapists seek to keep them fresh, innovative, and invested in their practice, thus providing the profession with additional information regarding recruitment and retention issues.

Within occupational therapy, mechanisms have been designed by which we can describe leadership and recognize leaders. We give awards to those who demonstrate leadership within the national organization, the legislative and health care environment, and the academic world of research. An understanding of the qualities and characteristics that contribute to outstanding performance among master clinicians, excellent practitioners, and leaders will require definition and clarification of these behaviors, their parameters, and their relationship. Who are master clinicians in occupational therapy? Who are leaders? What characteristics and qualities do they have that propel them to these high levels of excellence in performance? What kinds of experiences do they have? How do they think, reason, and solve problems? How are master clinicians, excellent practitioners, and leaders the same? How are they different? These are among the questions to be answered as we seek to understand the behavior of advanced clinicians.

\section{Defining the Concepts}

The systematic attempt to define and develop theory about mastery, excellence, and leadership is a contemporary phenomenon. Historically, social status defined one's position relative to societal standards. Because stratification of society was based on heredity, not action, human performance was not considered a determinant of social worth, excellence, or leadership (Benner, 1984; DePoy, 1988; Gardner, 1984; McClelland, 1981). However, current theorists (Benner, 1984; Gardner, 1984; Peters \& Waterman, 1982; Sudnow, 1978) in a multitude of disciplines and traditions have begun to examine excellence and related constructs from several different perspectives, including individual, environmental, and systems approaches.

\section{Mastery}

In investigating mastery, authors have considered the specific traits, knowledge, experience, style, and judgment of the individual practitioner; the clinical behaviors that are practiced; the effects of clinical actions on the patients that are served; and the ultimate effect of the practitioner's practice on the profession as a whole (DePoy, 1988). Among occupational therapy clinical masters, key factors include a common identifiable ideology of occupation; a highly developed knowledge base founded on extensive and varied experience that is grounded in occupation; and a set of essential behaviors, actions, and processes uniquely actualized by individual style (DePoy, 1988).

\section{Excellence}

According to Gardner (1984), excellence is a function of the interaction of the intellect, emotions, personality, and adaptability of the individual to environmental challenges. McClelland (1981) suggested that excellence is a human achievement in which a person is motivated to view and resolve problems in nontraditional ways. These challenges may be set forth by the deviation of a particular problem, institution, or society as a whole from that which is expected.

\section{Leadership}

Leadership involves not only an individual, but an individual's exercise of influence over others (Dwyer, 1987). Of 
the many theories of leadership, none has characterized the essence of leadership in varying contexts. Blau (1966), who studied organizational leadership, suggested that leadership is a mutual social interaction in which leadership status is bestowed in exchange for needed expertise brought by the leader to a group. Others have posited the trait and contingency approaches to leadership, indicating that leadership skill is innate and can be exercised, provided that a favorable context and contingencies exist (Bennis \& Nanus, 1985; Fiedler, 1981; Yukl, 1981).

To understand the occupational therapists who exemplify a practice that is masterful and excellent and who demonstrate leadership qualities, we used a qualitative research methodology. Bryman, Bresnen, Beardsworth, and Keil (1988) have suggested the use of qualitative methods that focus on the phenomenology of the subject under study. These methods can "expose" rather than "impose" (p. 16) and can describe holistically, thereby promoting a more complete understanding of the phenomena under investigation.

\section{Method}

Because a growing body of literature on mastery, leadership, and excellence exists, a research design that integrated naturalistic principles with a semistructured interview was used to answer the following research questions:

1. What are the common and distinguishing elements of mastery in occupational therapy?

2. What are the common and distinguishing elements of excellence in occupational therapy?

3. What are the common and distinguishing elements of leadership in occupational therapy?

4. What are the relationships among mastery, excellence, and leadership in occupational therapy?

Existing descriptions of mastery and leadership (Bennis \& Nanus, 1985) and a previously developed mastery interview (DePoy, 1988) were used as a foundation for the semistructured interview questions, whereas principles of an unstructured ethnographic interview (Spradley, 1980) were used to guide the remainder of the data collection.

\section{Investigators and Sample}

The research team consisted of eight occupational therapy students enrolled in an advanced master's class designed to explore issues of mastery, excellence, and leadership in occupational therapy practice. All of these students were experienced practitioners and had used interview techniques in their practice.

Each student identified a clinician or clinicians who had practice experience and who met the student's per- ceptions of mastery, excellence, and leadership. The student then telephoned the clinician to explain the study, recruit him or her for the study, and finalize consent. Use of the above criteria (i.e., being identified as a master, leader, or excellent practitioner) as well as the conditions of being willing and able to contribute the necessary time and effort resulted in a sample of 10 respondents -8 women and 2 men. Six were clinicians with varying degrees of administrative or supervisory responsibilities, and 4 were full-time administrators (see Table 1).

\section{Instrument}

The students developed the interview instrument in class. The interview consisted of semistructured and openended questions. Sixteen semistructured questions, derived from work by DePoy (1988), were used to obtain data on known constructs of mastery and leadership. Ten open-ended questions and related probe questions were developed to elicit an understanding of the context of mastery and leadership and to further reveal how mastery and leadership could differ in varying areas of practice.

\section{Data Collection and Analysis}

Seven of the subjects were interviewed in person and 3 by telephone. None of the subjects were aware of the identity of the other study subjects. The tape-recorded interviews lasted approximately $120 \mathrm{~min}$ and were transcribed. After the interview, 7 of the subjects were observed in practice for a period of 35 to $40 \mathrm{~min}$; the remaining 3 subjects were unable to arrange for observations. Field notes were used to describe the action and interaction of each therapist in the therapeutic or administrative situation

While the students performed their own data analysis, we independently conducted thematic and taxonomic analyses of the data. The taxonomic analysis was bounded by the domains for mastery and leadership. Themes in each domain were identified. As this analysis proceeded, the two broader domains of public and private emerged

Table 1

Profile of Study Subjects $(N=10)$

\begin{tabular}{cllc}
\hline Subject & \multicolumn{1}{c}{ Area of Practice } & Degree & Sex \\
\cline { 1 - 3 } 1 & Pediatrics & $\mathrm{PhD}$ & $\mathrm{M}$ \\
2 & Adult Rehabilitation & $\mathrm{MS}$ & $\mathrm{M}$ \\
3 & Adult Rehabilitation Administration & $\mathrm{MS}$ & $\mathrm{F}$ \\
4 & Adult Rehabilitation Administration & $\mathrm{MS}$ & $\mathrm{F}$ \\
5 & Adult Rehabilitation Administration & $\mathrm{MA}$ & $\mathrm{F}$ \\
6 & Rehabilitation Administration & $\mathrm{MA}$ & $\mathrm{F}$ \\
7 & Hand Rehabilitation & $\mathrm{BS}$ & $\mathrm{F}$ \\
8 & Rehabilitation & Certificate & $\mathrm{F}$ \\
9 & Adults - Brain Injury & $\mathrm{BS}$ & $\mathrm{F}$ \\
10 & Pediatrics & $\mathrm{MA}$ & $\mathrm{F}$ \\
\hline
\end{tabular}

Note. $\mathrm{PhD}=$ doctor of philosophy; $\mathrm{MS}=$ master of science; $\mathrm{MA}=$ master of arts; $B S=$ bachelor of science. $M=$ male; $F=$ female. 
to encompass the categories of mastery and leadership. After performing individual analyses, the two authors synthesized their findings.

\section{Results}

The transcripts and field notes produced extensive data. Figure 1 presents a taxonomy of mastery, excellence, and leadership and the relationship among them. It shows the organization of the data into two categories: the public domain and the private domain. Repetitive themes in the interview data reveal that the subjects defined excellence and leadership as public activities, that is, to be considered an excellent practitioner or leader, one has to be compared to a set of socially determined and accepted standards. Excellence is achieved when one surpasses externally recognized standards of competence and "goodness" in professional practice, thus placing excellence in the public arena. Similarly, leadership can only be recognized and exercised in the presence of others, which places it in the public domain as well.

The link between excellence and leadership seems to lie in recognition. Leaders and excellent practitioners are recognized by others on the basis of established standards and criteria and formal recognition mechanisms (e.g., awards, commendations). The key elements differentiating leadership from excellence are power and influence. The excellent individual seems to display vision and constant striving to become better than a previously established standard, whereas the leader promotes excel- lence, without necessarily demonstrating it by exercising influence and power. This difference can be demonstrated with an example in the area of program development. The excellent practitioner's contribution to program development lies primarily in the construction and enactment of an innovative vision, whereas the leader may approach program development by exerting power in securing space, funds, and personnel in order to fuel the program and make it a reality. Although it would be most useful to have information on leadership style and its effect on different domains of influence (e.g., program development, organizational issues, fiscal management), data highlighting this phenomenon did not emerge in this study,

Mastery, on the other hand, is located in the private domain; it can be accomplished individually and is a function of personal knowing, action, experience, and thinking. The master and the patient may be the only persons who recognize mastery within the privacy of treatment. The master is characterized by six behaviors: experience, creative reasoning, commitment, knowledge, confidence, and vision. From experience, the master clinician often reasons and solves problems based on a "knowing in action" stance (Schön, 1983, p. 59). In this situation, the clinicians may know more than they can say about the reasons they choose to select or modify certain activities on the basis of the patient's reaction to the experience. Master clinicians also possess a kind of thinking in action, which is a function of creative reasoning. They seem to be able to think on their feet when interacting with patients.

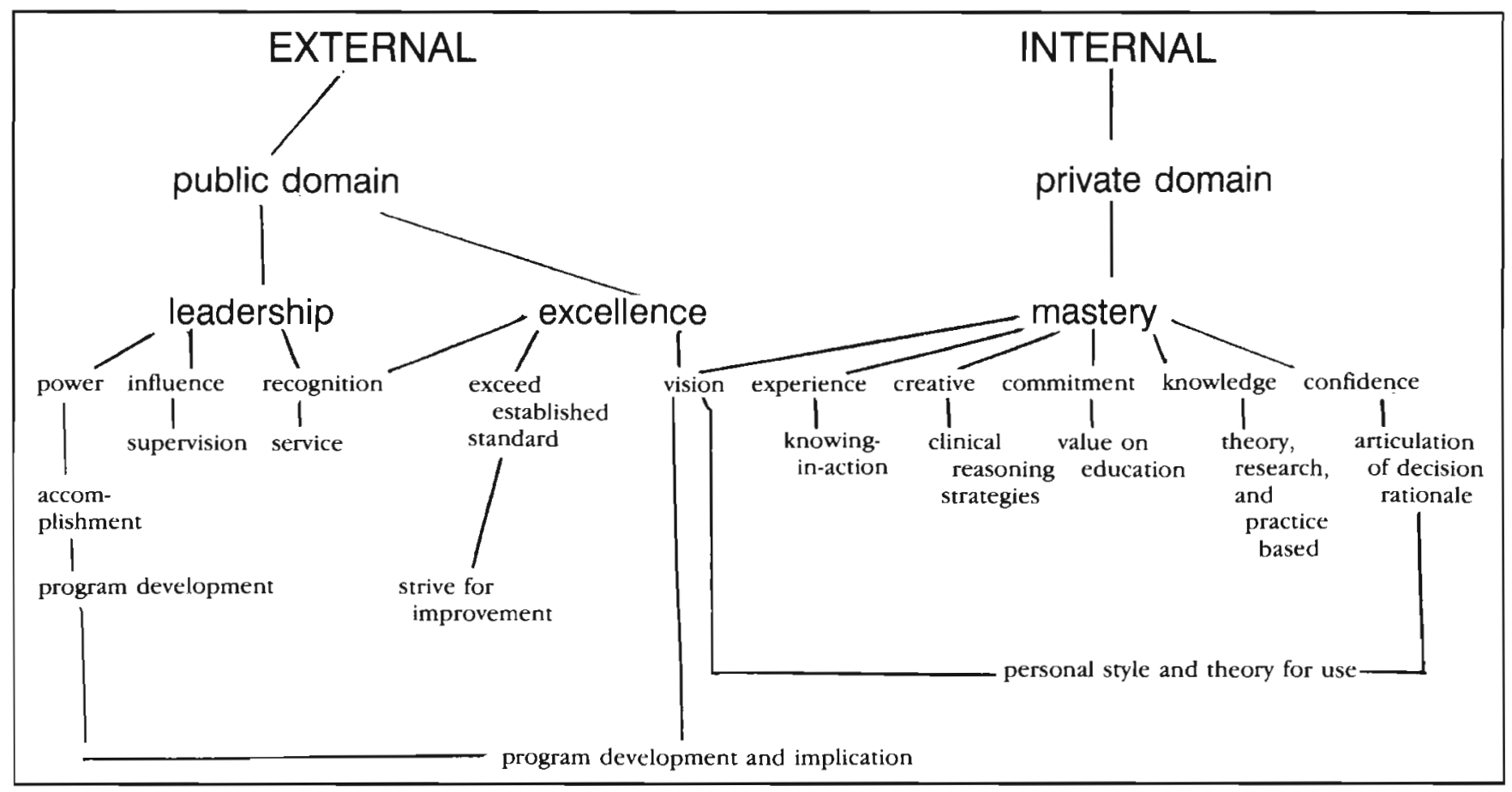

Figure 1. Taxonomy of mastery, excellence, and leadership in occupational therapy practice. Note. Excellence is defined as performance judged against externally defined standards; leadership, as an assumed or recognized position of influence and power; and mastery, as an internally generated drive for quality. 
The master clinician reports commitment to the profession, values professional development with particular attention to education, and reports basing practice on a body of knowledge that is grounded in theory and research. The subjects referred to additional courses they had taken, books and articles they had studied, and workshops they attended as an ongoing process for adding to their skills in and knowledge of caring for patients. All of the subjects were aware of their mastery and exhibited professional confidence. They used a personal style and unique theory for practice.

Mastery and excellence seem to be linked by vision. Both the master clinicians and the excellent practitioners displayed visionary thinking. Whereas the master clinician applies this vision to personal practice, however, the excellent practitioner applies it to public arenas, such as program development.

Although the taxonomy aims at a definition and differentiation of mastery, excellence, and leadership, some informants displayed two or all three constructs in their professional lives.

\section{Discussion}

This study has several limitations. First, the sample is limited because the selection of masters was based on individuals' perceptions and the informants' reputations. Although a commonsense recognition of mastery, excellence, and leadership is helpful in developing an understanding of these phenomena, the sample may not have revealed all of the facets of mastery, excellence, and leadership. Second, the limited amount of time for interviews and observation may have not been sufficient for total saturation. Third, due to time constraints, the investigators did not recheck their conclusions with their informants. We therefore caution the reader to interpret the findings as relevant to the informants and to the development of theory only.

The findings suggest several important points. First, consistent with previous research, master clinicians seem to display a set of common characteristics, but each demonstrates a personal style, without which mastery would not be possible. Second, mastery in clinical practice does not depend on recognition from other professionals. For the master clinician, the internal vision of practice provides the motive for and goal of practice. Third, excellence appears to be a public recognition of mastery; when master clinicians move beyond individual treatment and use public arenas to share their innovative vision and practice (e.g., workshops, publications), they provide opportunities for their peers and other professionals to see and experience their skills. When this happens, others recognize it and label it as excellence. Without an opportunity to demonstrate excellence in a public arena, the master may not be known.

Leaders are not necessarily master clinicians or ex- cellent practitioners. Conversely, master clinicians and excellent practitioners are not necessarily leaders. Leaders produce programmatic and clinical results through influence and power. The vision exhibited by the master clinician and the excellent practitioner by itself is not sufficient to create change in the profession, nor is influence and power sufficient to create growth and improvement in the profession. The leader and the excellent practitioner need each other to promote change that will move the profession in a positive direction. If leadership and excellence are not embodied within the same individual, then an alliance or a network can be formed as a vehicle through which professional growth of the practitioner and the profession will be most effectively realized.

This study has implications for ongoing clinician and leader development. First, to ensure that novices and other developing therapists who have not yet achieved mastery will recognize mastery, we must give them opportunities to observe both master clinicians and excellent practitioners, to converse with them, and to compare them as a means of understanding their differences and the development of their behaviors. The creation of these guided observations will allow occupational therapists to formulate notions concerning the developmental steps required in the achievement of mastery, excellence, and leadership. Additionally, the results of opportunities to observe and examine mastery, excellence, and leadership can inform curriculum development at both the undergraduate and graduate levels of professional education and contribute to the design of course work that will stimulate research and professional development.

\section{Acknowledgments}

We thank the student researchers from the Spring 1990 Clinical Leadership course, Department of Occupational Therapy, Thomas Jefferson University, Philadelphia, and the occupational therapists who participated in the interview portion of the course.

\section{References}

Barris, R. (1987). Clinical reasoning in psychosocial occupational therapy: The evaluation process. Occupational Therapy Joumal of Research, 7, 147-162.

Benner, P. (1984). From novice to expert. Menlo Park, CA: Addison-Wesley.

Benner, P., \& Tanner, C. (1987). Clinical judgement: How expert nurses use intuition. American Joumal of Nursing, 87, 23-31.

Bennis, W., \& Nanus, B. (1985). Leadership: The strategies for taking charge. New York: Harper \& Row.

Blau, P. M. (1966). Issues in organization. In D. Katz \& D. Kahn (Eds.), The social psychology of organizations (pp. 112116). New York: Wiley.

Bryman, A., Bresnen, M., Beardsworth, A., \& Keil, T. (1988). Qualitative research and the study of leadership. Human Relations, 41, 13-30.

Burke, J. P. (1989). Selecting evaluation tools I. In C. B. Royeen (Ed.), AOTA self siudy series: Assessing function (No. 3). Rockville, MD: American Occupational Therapy Association. Cohn, E. S. (1989). Fieldwork education: Shaping a founda- 
tion for clinical reasoning. American Joumal of Occupational Therapy, 43, 240-244.

DePoy, E. (1988). The professionalizalion of occupational therapy: Using a Delphi survey approach to the development of a model of clinical mastery. Unpublished doctoral dissertation, University of Pennsylvania, Philadelphia

DePoy, E. (1990). Mastery in clinical occupational therapy. American Journal of Occupational Therapy, 44, 415-422.

Dwyer, C. (1987). Managing people. Unpublished manuscript, University of Pennsylvania, Graduate School of Education, Philadelphia.

Fiedler, F. (1981). Fiedler's Contingency Model of Leadership. In G. A. Yukl (Ed.), Leadership in organizalions (pp. 132169). Englewood Cliffs, NJ: Prentice Hall.

Fleming, M. H. (1991). The therapist with the three-track mind. American Journal of Occupational Therapy, 45, 10071014.

Gardner, J. (1984). Excellence. New York: Norton.

Gillette, N., \& Mattingly, C. (1987). The Foundation - Clinical reasoning in occupational therapy. American Journal of Occupational Therapy, 41, 399-400.

Mattingly, C. (1990). Occupational therapy as a collaborative practice. In M. Fleming (Ed.), Proceedings of the Institute on Clinical Reasoning for occupational therapy educators (pp. 1-3). Medford, MA: Tufts University.

McClelland, M. (1981). Towards clinical excellence in nurs- ing: A program for the development of nurses. Nursing Adminisiration Quarterly, 7, 26-29.

Neistadt, M. E. (1987). Classroom as clinic: A model for teaching clinical reasoning in occupational therapy education. American Joumal of Occupational Therapy, 41, 631-637

Neuhaus, B. E. (1988). Ethical considerations in clinical reasoning: The impact of technology and cost containment. American Joumal of Occupational Therapy, 42, 288-294.

Parham, D. (1987). Nationally Speaking-Toward professionalism: The reflective therapist. American Joumal of Occupational Therapy, 41, 555-561.

Peters, T. J., \& Waterman, R. H. (1982). In search of excellence. New York: Warner.

Rogers, J., \& Masagatani, G. (1982). Clinical reasoning of occupational therapists during the initial assessment of physically disabled patients. Occupational Therapy Journal of Research, 2, 195-219. Basic

Schön, D. (1983). The reflective practitioner. New York:

Spradley, I. (1980). Participant observation. New York: Holt, Rinehart \& Winston.

Sudnow, D. (1978). Ways of the hand. Cambridge, MA: Harvard University Press.

Yukl, G. A. (1981). Leadership in organizations. Englewood Cliffs, NJ: Prentice Hall.

\title{
Surgery and Rehabilitation of the Hand.'92 Symposium and Workshop
}

\author{
Sponsored by \\ Hand Rehabilitation Foundation and Jefferson Medical College \\ of Thomas Jefferson University \\ Honored Senior Professor \\ Harry J. Buncke, M.D. \\ San Francisco, California
}

March 28-31, 1992, Philadelphia, Pennsylvania

Course Chairmen

James M. Hunter, M.D. Lawrence H. Schneider, M.D. Evelyn J. Mackin, P.T.

\section{Anatomy of the Upper Limb Demonstrated in 3-Dimensional Projection Anatomy Laboratory Workshops: Shoulder and Hand Closed Circuit TV-Live Surgery: Active Tendon Reconstruction}

A symposium and workshop designed to present to the surgeon, resident, physiatrist, physical and occupational therapist and registered nurse a unique opportunity to correlate the concepts, indications, surgical techniques, and pre- and post-operative care of the injured and disabled upper extremity. "Hands on" workshops and panel discusions will complement the didactic session. Information: Evelyn J. Mackin, PT, Hand Rehabilitation Foundation, 901 Wainut St., Philadelphia, PA 19107 (215/925-4579) 